\title{
Presentation
}

\section{The High Luminosity LHC Project}

\author{
Rossi, Lucio (CERN)
}

04 December 2013

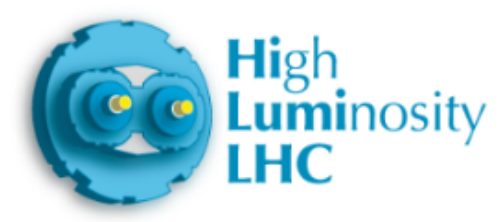

The HiLumi LHC Design Study is included in the High Luminosity LHC project and is partly funded by the European Commission within the Framework Programme 7 Capacities Specific Programme, Grant Agreement 284404.

This work is part of HiLumi LHC Work Package 1: Project Management \& Technical Coordination.

The electronic version of this HiLumi LHC Publication is available via the HiLumi LHC web site $<$ http://hilumilhc.web.cern.ch> or on the CERN Document Server at the following URL: $<$ http://cds.cern.ch/search?p=CERN-ACC-SLIDE-2013-045> 


\section{SUPERCONDUCTING TECHNOLOGIES}

FOR THE NEXT GENERATION

OF ACCELERATORS

WORKSHOP

- IEEE

High

Luminosity CSC

Council on Superconductivity

Distinguished

Lecturer 2013

\section{Lucio Rossi}

The High Luminosity LHC Project 政 


\section{Content}

Energy and luminosty

- Present LHC and luminosity evolution

Reasons for the upgrade

Luminosity Upgrade: the main ingredients"

-FP7 HiLumi Design Study

- Further evolution: the Energy upgrade

- HL-LHC main technologies 


\section{The two Discovery Frontiers}

2 routes to new knowledge about the fundamental structure of the matter

\section{High Energy Frontier}

New phenomena (new particles) created when the "usable" energy > $\mathrm{mc}^{2}[\times 2]$

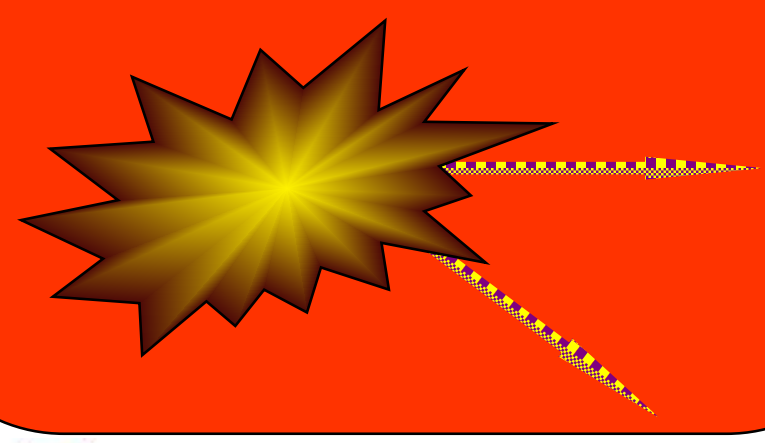

\section{High Precision Frontier}

Known phenomena studied with high precision may show inconsistencies with theory
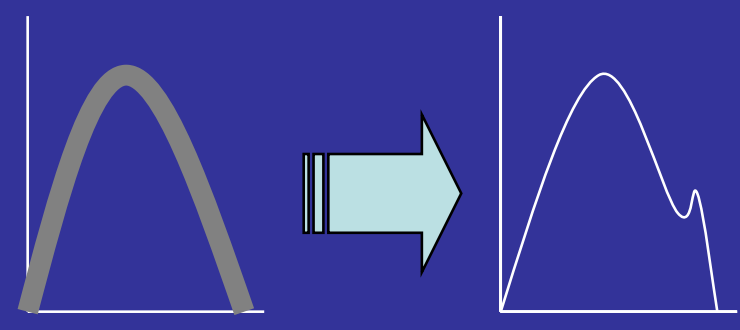


\section{LHC and Hadron colliders}

Hadron colliders are the typical tooling for High Energy Frontiers because the total energy is so large: $8 \mathrm{TeV}$ (and later $14 \mathrm{TeV}$ )

However all quarks and gluons inside the protons can collide each other $\rightarrow$ the energy per collision is subdivided : $8 \mathrm{TeV} / \mathrm{N}$

So there are many events and many traces in a $p-p$ collision
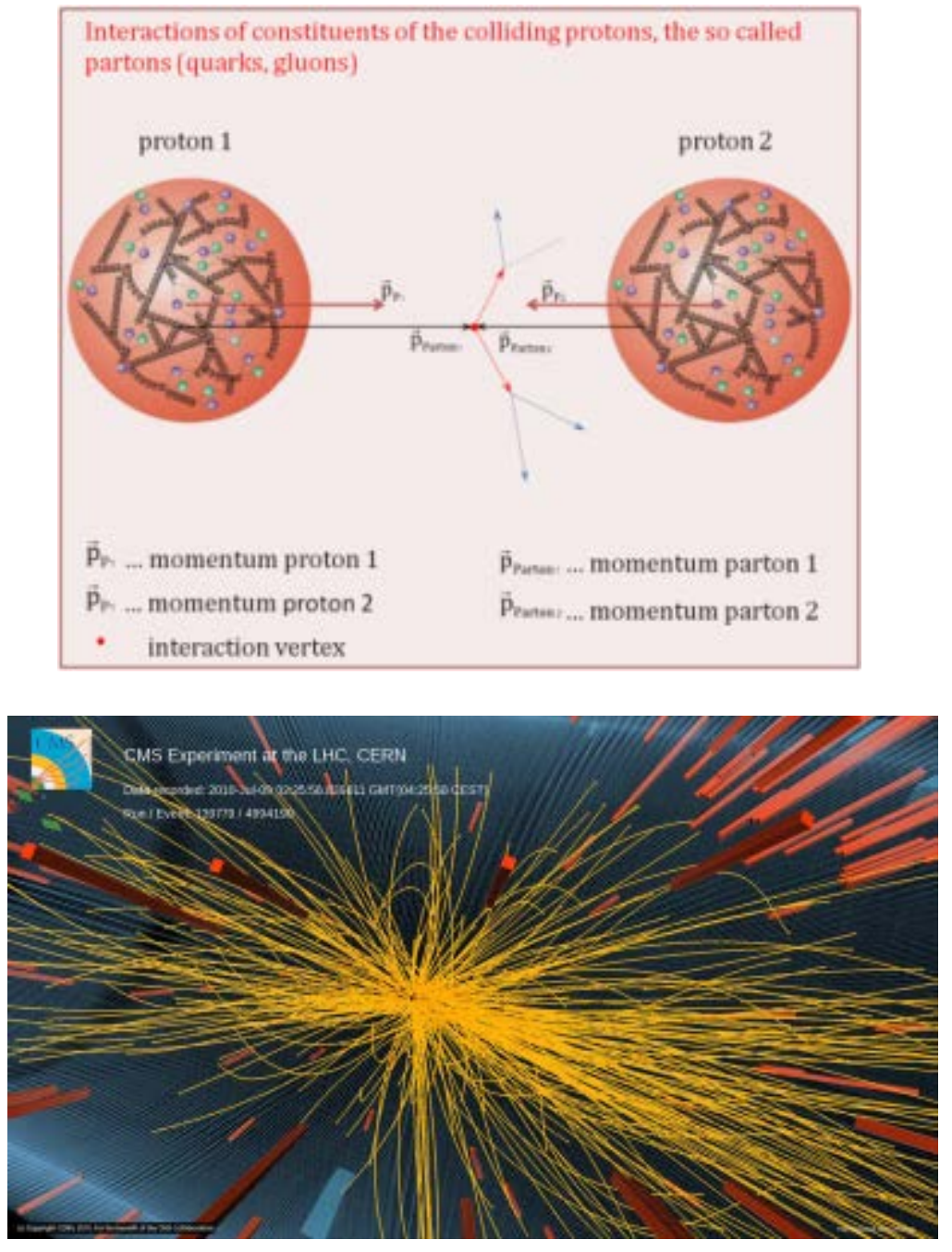


\section{The interesting very rare events}

Interesting events are like a needle in a haystack: very rare.

A Higgs happens 1 each $10^{12}$ events!

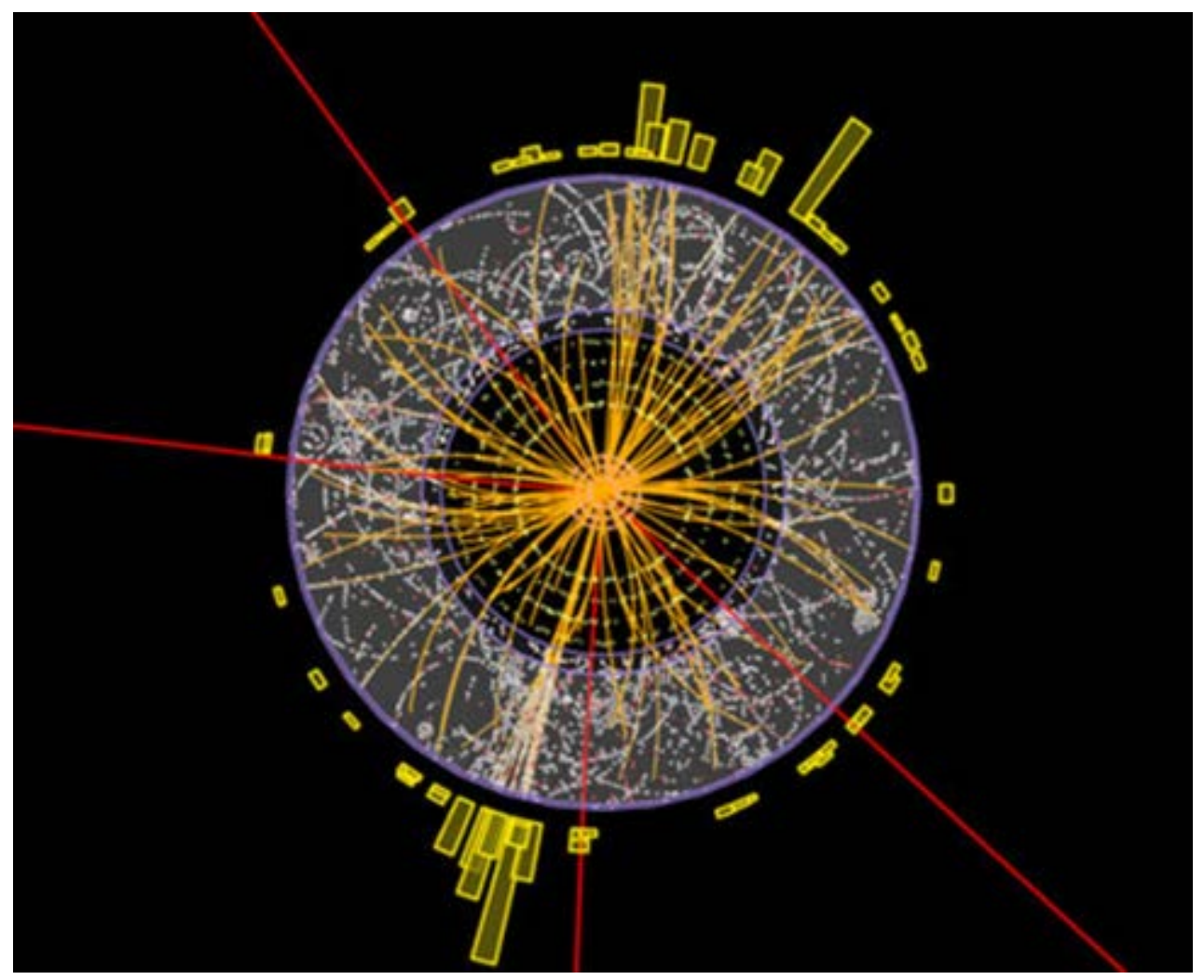




\section{Luminosity is $\propto$ to collision rate}

After energy, Lumi is the most importnat parameters of a collider.

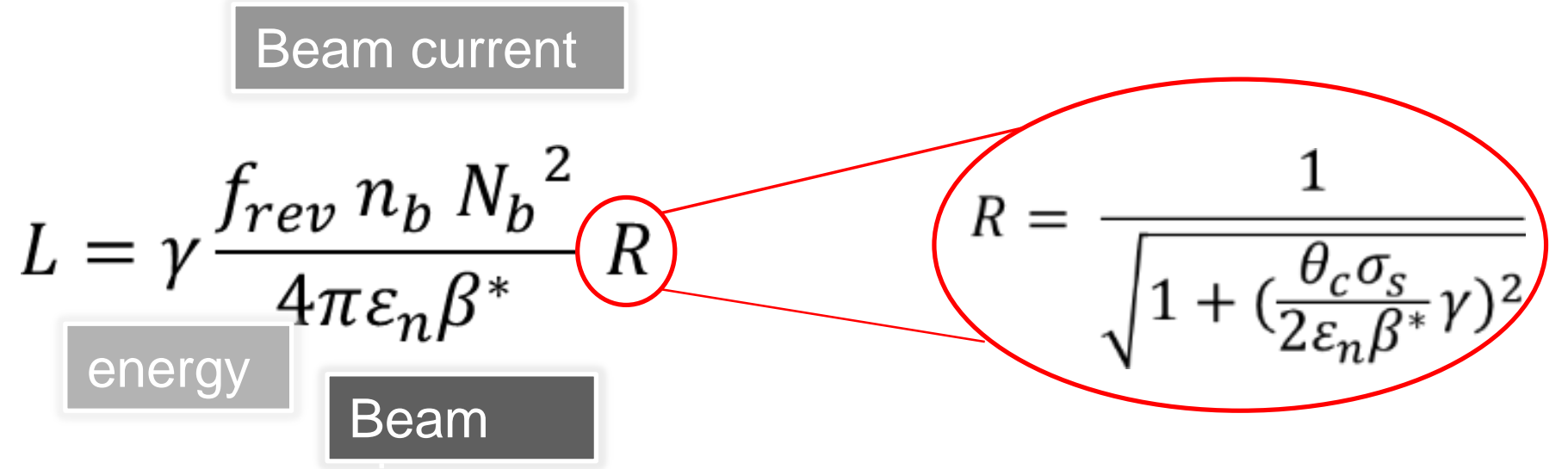

Beam current and emittance: involve Inj chain and whole ring $\beta^{*}$ involve «only» 2 IRs, 600 m (but ATS...)

$$
L_{0}=1 \cdot 10^{34} \mathrm{~cm}^{-2} \mathrm{~s}^{-1}
$$

LHC has been designed for $L_{0}$

All systems have singularly designed tentatively for ultimate $2 \mathrm{~L}_{0}$ (almost...)

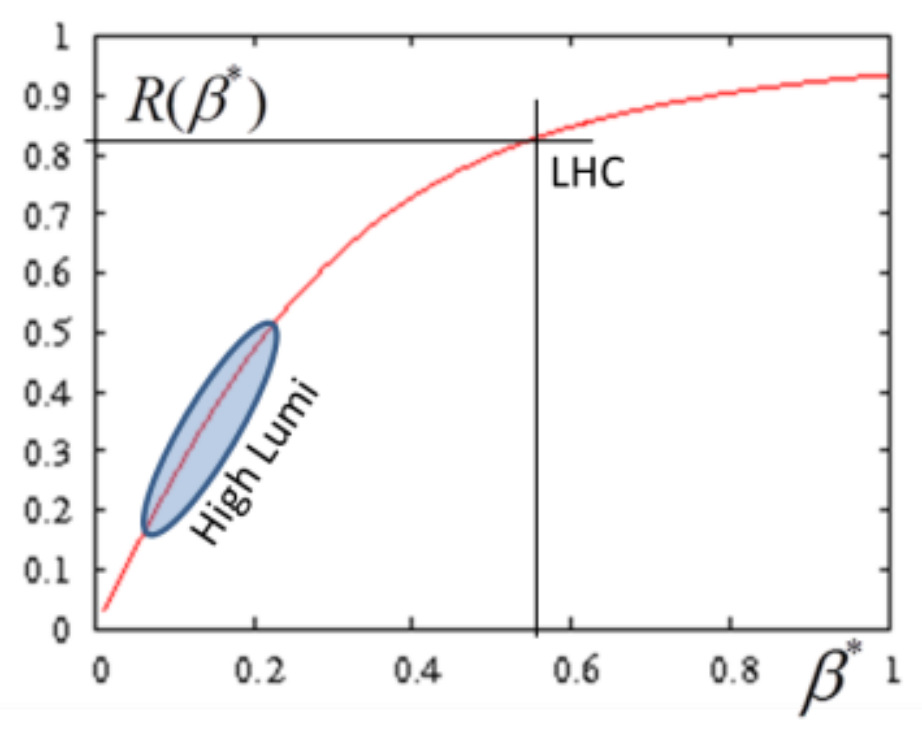




\section{Integrated Luminosity in LHC $\left(\mathrm{fb}^{-1}\right)$}

In 2011: at $7 \mathrm{TeV}$ accumulated $5.6 \mathrm{fb}^{-1}$
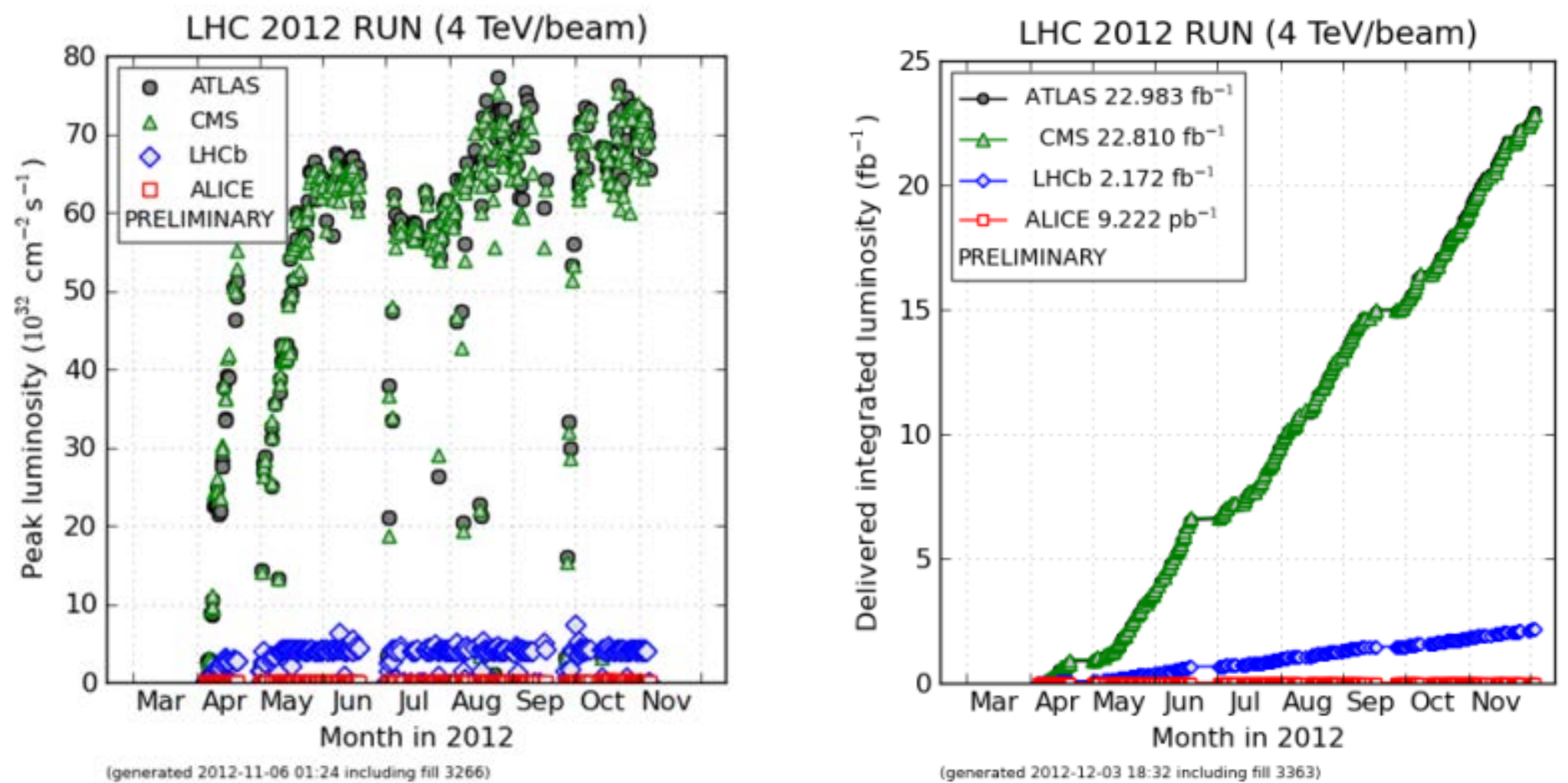
Magnets: 11 T dipoles, 12-13 Quads

Crab Cavities : femtosecond accuracy

SC links: 150-200 kA, 5 kV, 300-700 long

New cryogenic plants and other equipment

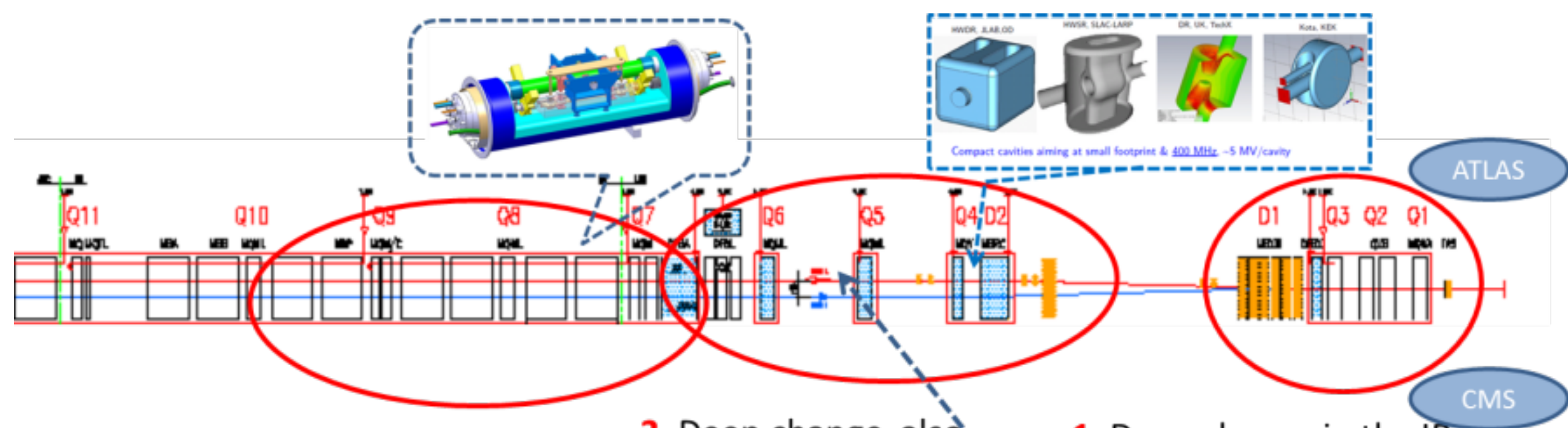

3. For collimation we

2. Deep change alsò, need to change also this part, DS in the continuous cryostat matching section: Magnets, collimators and CC

1. Deep change in the IRs and interface to detectors; relocation of Power Supply

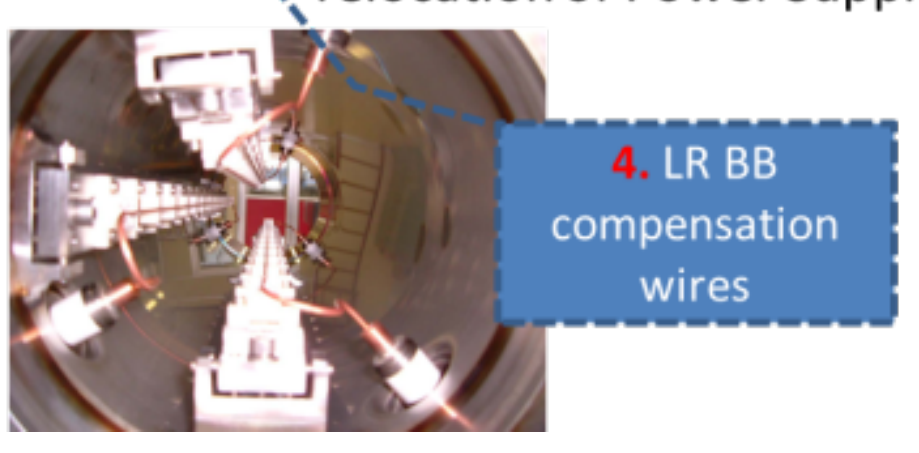




\section{Changing $>1.2 \mathrm{~km}$ of LHC...}

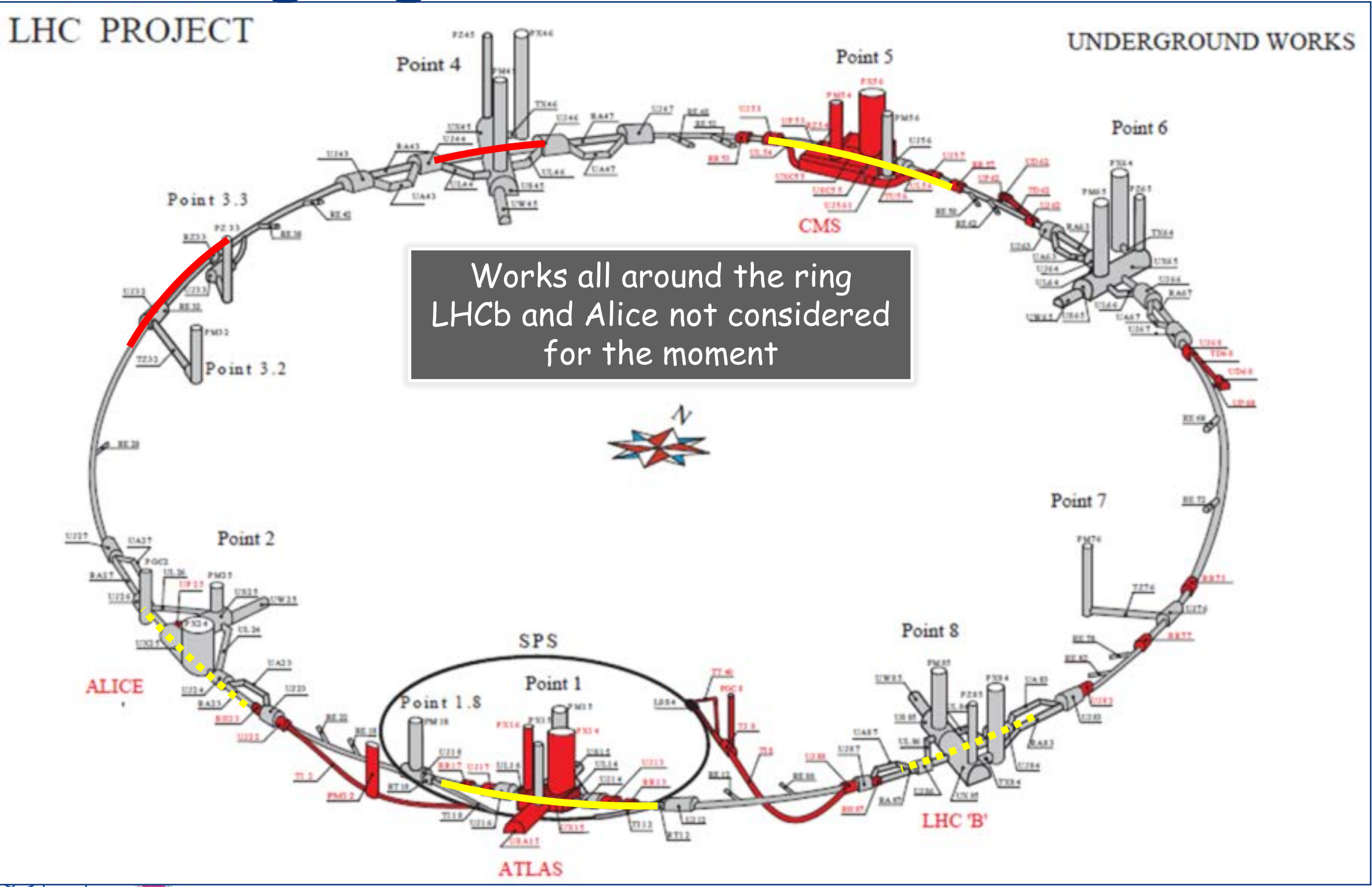




\section{Some of the hardware to change...}

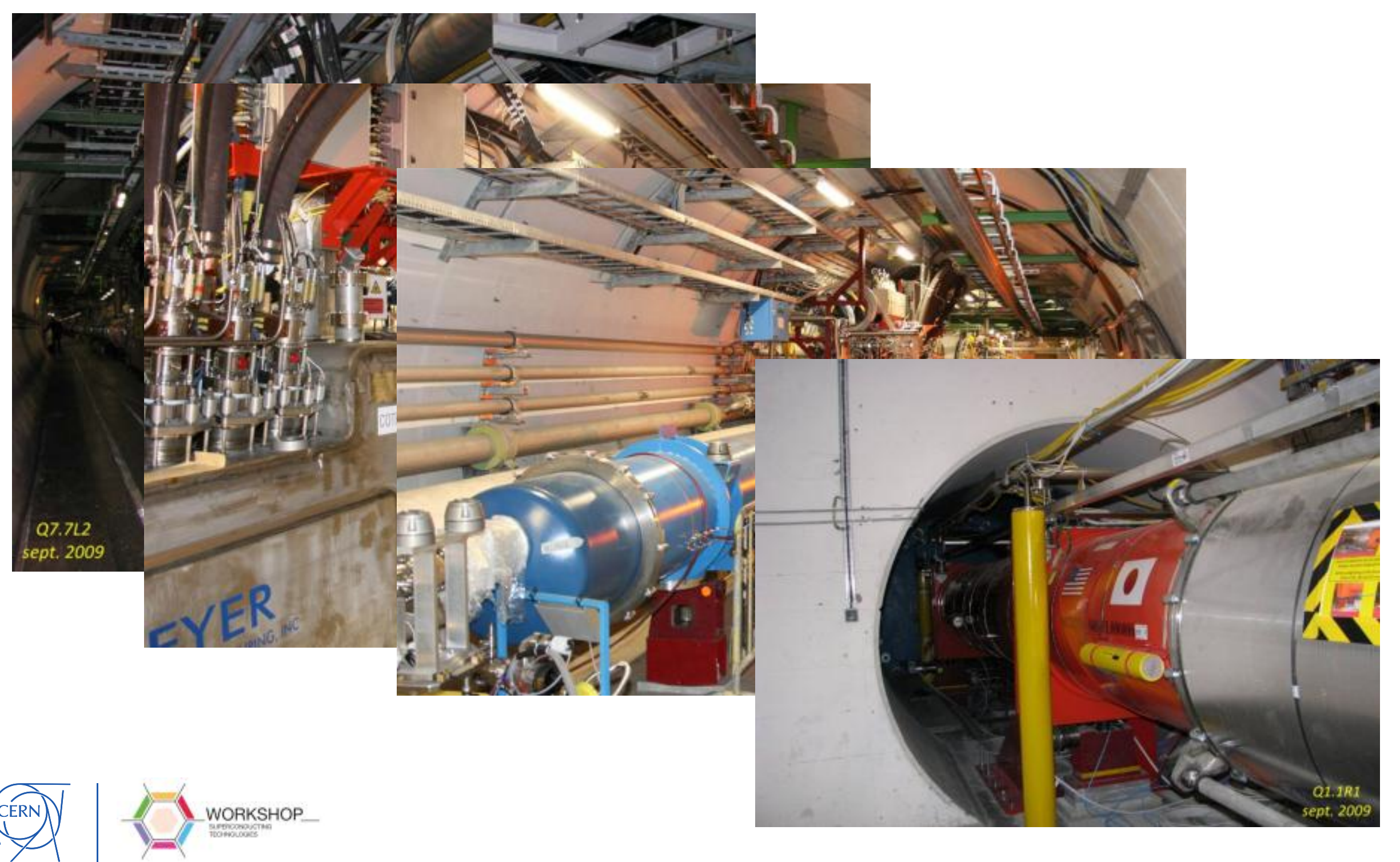




\section{Extending the lifetime of LHC by}

10-12 years...

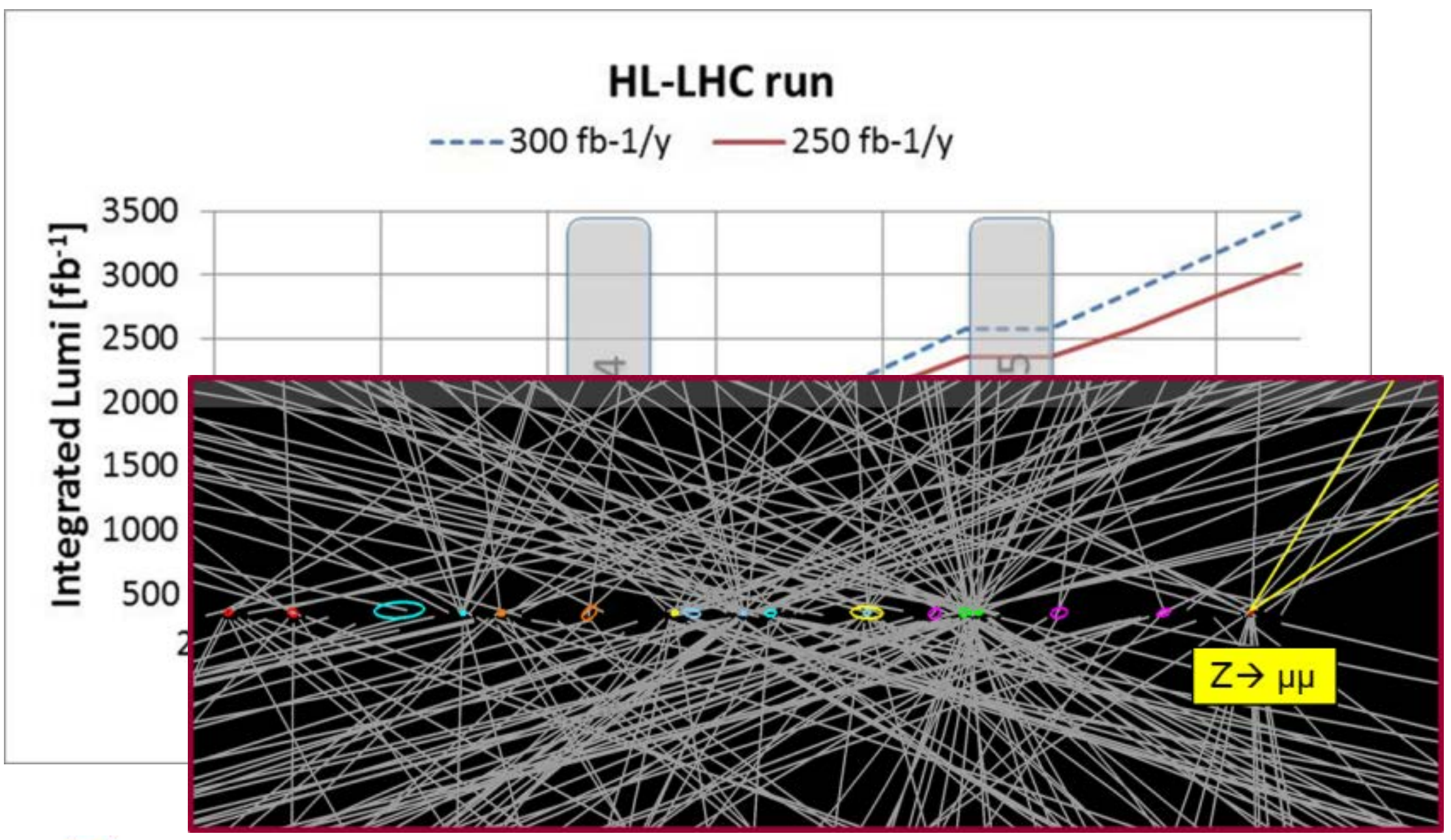

(2) 


\section{Budget FP7 HiLumi LHC (EU funded Design Study) and the whole project HL-LHC}

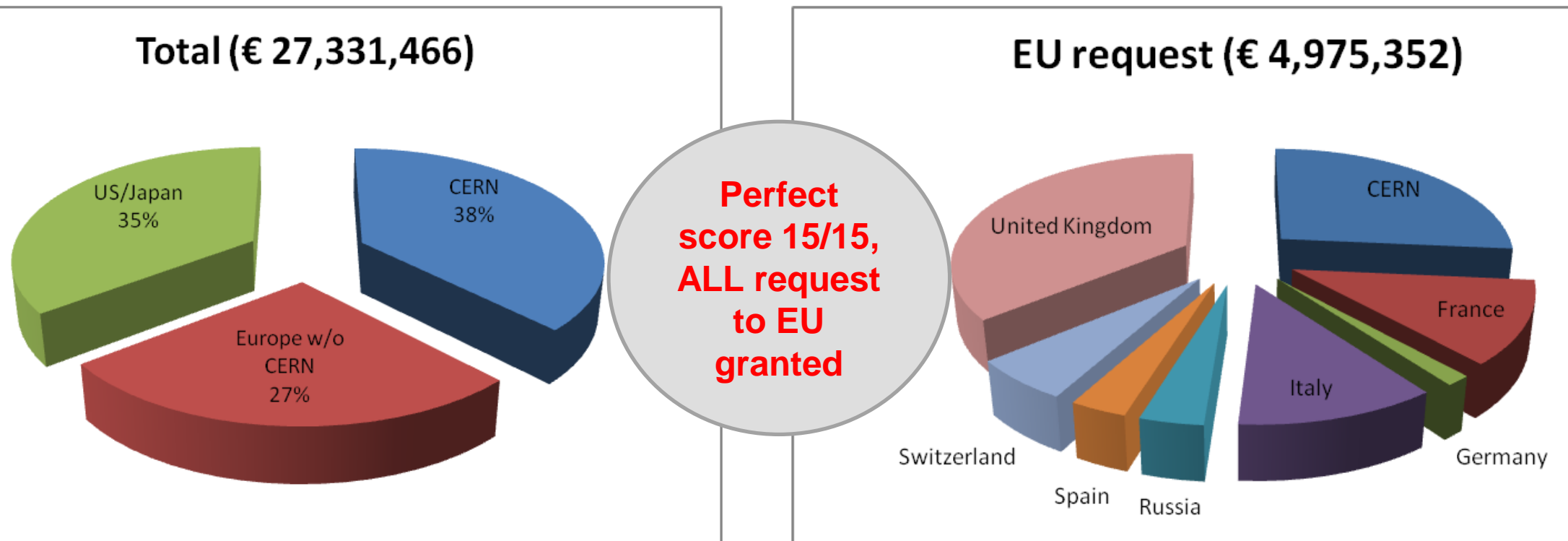

Estimated cost for the the whole HL-LHC over 10 years in M€ (October 2010) No infrastructure (100 MCHF)

\begin{tabular}{|l|r|r|} 
& $\begin{array}{r}\text { Design in FP7 } \\
\text { HiLumi }\end{array}$ & $\begin{array}{r}\text { Extra effort } \\
\text { for Design }\end{array}$ \\
\hline W1-WP6 & 27 & 10 \\
\hline WP7-12 & 0 & 15 \\
\hline Other & 0 & 5 \\
\hline TOT & 27 & 30 \\
\hline
\end{tabular}

R\&D and Industrialization

proto \& Construction

\begin{tabular}{|r|r|}
\hline TOT & Industry \\
\hline 287 & 160 \\
\hline 145 & 80 \\
\hline 65 & 40 \\
\hline 497 & 280 \\
\hline
\end{tabular}




\section{List of WP coordinators}

\begin{tabular}{|c|c|c|c|c|c|c|}
\hline & WP1 & WP2 & WP3 & WP4 & WP5 & WP6 \\
\hline & $\begin{array}{l}\text { MNGT } \\
\text { Management \& } \\
\text { Technical } \\
\text { Coordination }\end{array}$ & $\begin{array}{l}\text { APP } \\
\text { Accelerator } \\
\text { Physics \& } \\
\text { Performance }\end{array}$ & $\begin{array}{l}\text { MAG } \\
\text { Magnet } \\
\text { Design }\end{array}$ & $\begin{array}{l}\text { CC } \\
\text { Crab Cavities }\end{array}$ & $\begin{array}{l}\text { COL } \\
\text { IR Collimation }\end{array}$ & $\begin{array}{l}\text { CP } \\
\text { Cold Powering }\end{array}$ \\
\hline Coordinator & $\begin{array}{l}\text { Lucio Rossi } \\
\text { CERN }\end{array}$ & $\begin{array}{l}\text { Oliver Bruning } \\
\text { CERN }\end{array}$ & $\begin{array}{l}\text { Ezio Todesco } \\
\text { CERN }\end{array}$ & $\begin{array}{l}\text { Erk Jensen } \\
\text { CERN }\end{array}$ & $\begin{array}{l}\text { Ralph } \\
\text { Assmann } \\
\text { CERN }\end{array}$ & $\begin{array}{l}\text { Amalia } \\
\text { Ballarino } \\
\text { CERN }\end{array}$ \\
\hline $\begin{array}{l}\text { Co- } \\
\text { Coordinator }\end{array}$ & $\begin{array}{l}\text { Oliver Bruning } \\
\text { CERN }\end{array}$ & $\begin{array}{l}\text { Andy Wolski } \\
\text { UniLIV (UK) }\end{array}$ & $\begin{array}{l}\text { Gianluca Sabbi } \\
\text { LBNL (USA) }\end{array}$ & $\begin{array}{l}\text { Graeme Burt } \\
\text { UniLAN (UK) }\end{array}$ & $\begin{array}{l}\text { Grahame Blair } \\
\text { RHUL (UK) }\end{array}$ & $\begin{array}{l}\text { Francesco } \\
\text { Broggi } \\
\text { INFN (IT) }\end{array}$ \\
\hline
\end{tabular}

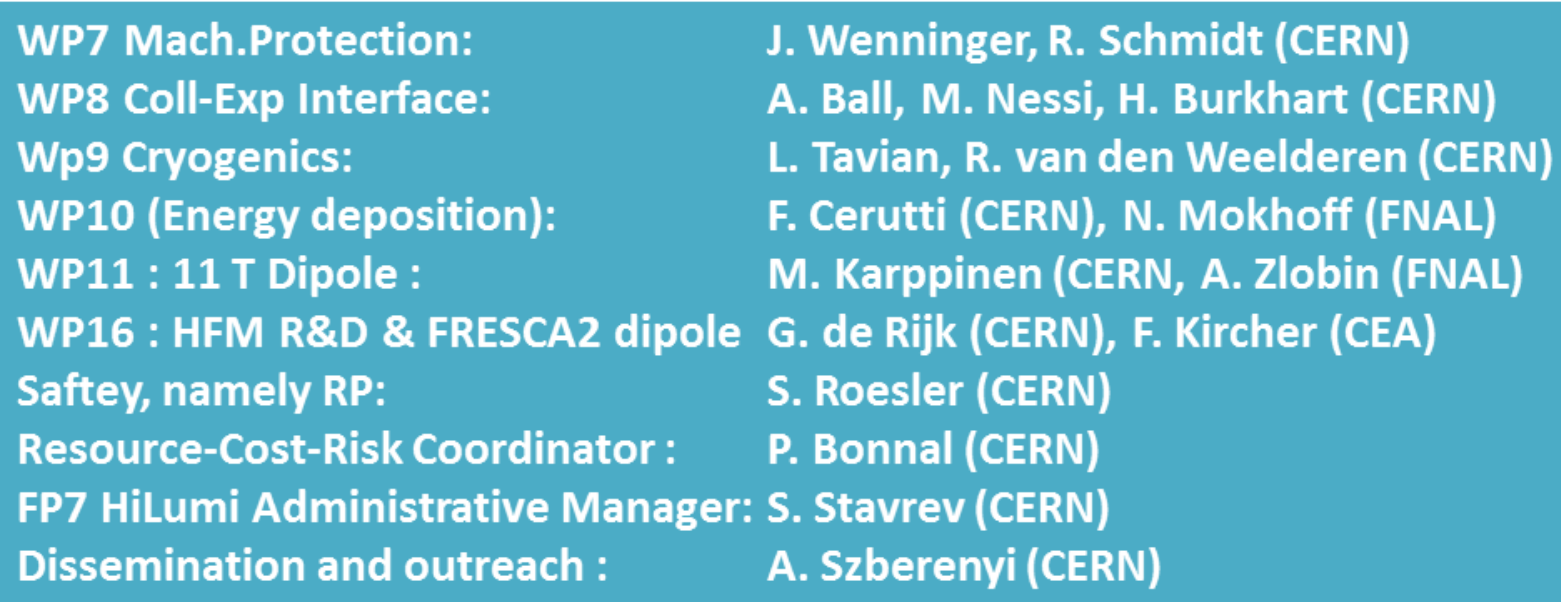




\section{And then? HiLumi isd also a prepration for another larger project: HE-LHC}

\section{The super-exploitation of the CERN compelx: Injectors, LEP/LHC tunnel, infrastructures}

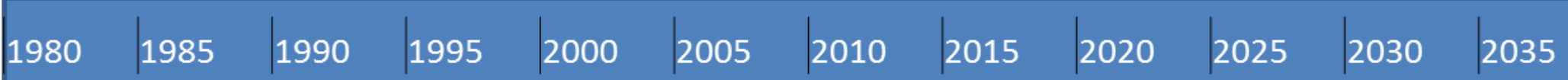

\begin{tabular}{l|l|l}
\hline LEP & Construct. & Physics Upgr \\
\hline
\end{tabular}

\begin{tabular}{l|l|l|l|l}
\hline LHC & Design, R\&D & Proto & Construct. & Physics \\
\cline { 2 - 3 }
\end{tabular}

HL-LHC

\begin{tabular}{|l|l|l|}
\hline Design, R\&D & Construct. & Physics \\
\hline
\end{tabular}

HE-LHC

\begin{tabular}{|l|l}
\hline Design, R\&D Proto $\quad$ Construct. \\
\hline
\end{tabular}




\section{Possible timeline for an HE-LHC}

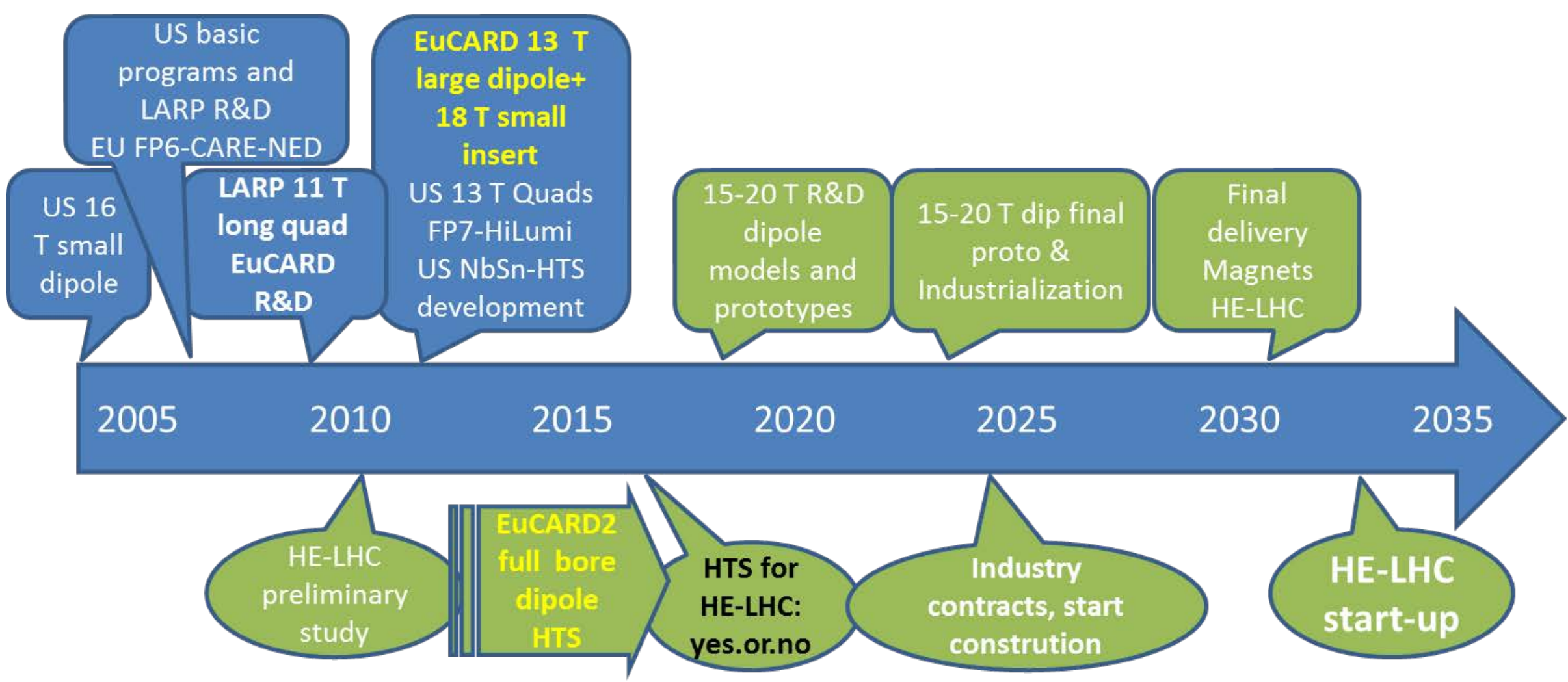




\section{FP7-EuCARD2 program approved}

start May 2012. WP10-Future Magnets

Develop 10 kA class HTS accelerator cables

Test in in a $5 \mathrm{~T}$ accelerator quality dipole

The aim is one day go into $16-10 \mathrm{~T}$ region
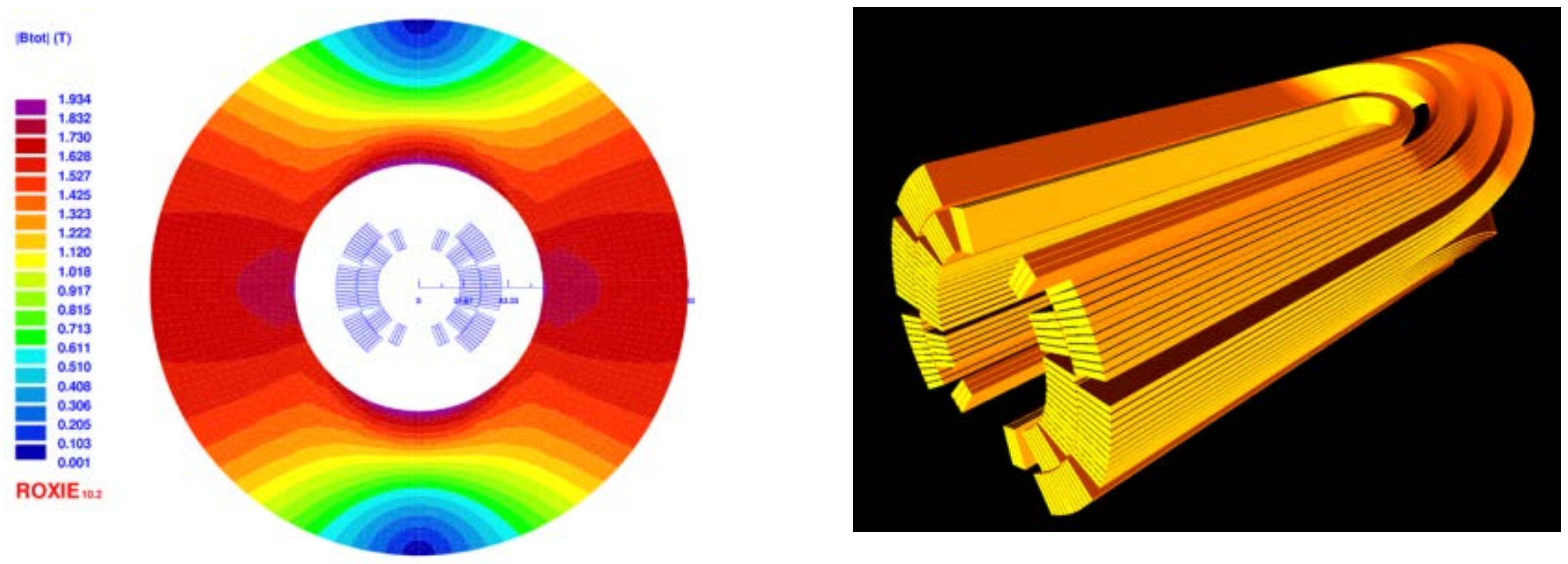


\section{HE-LHC in LHC tunnel or in $80 \mathrm{~km}$ new tunnel}

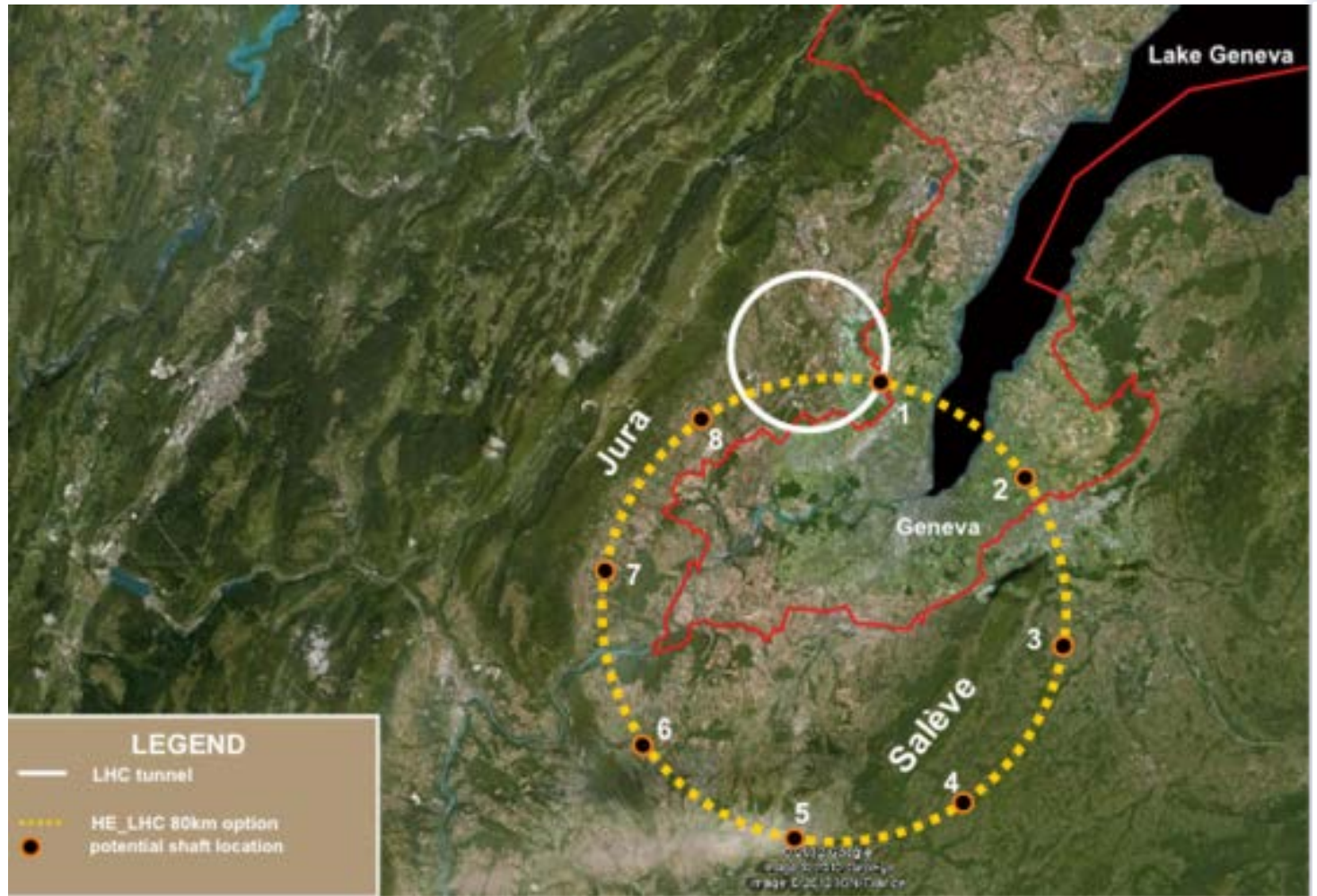

Whatever solution, only a vigorous Magnet R\&D (and on other equipment )will enable to go beyond LHC energy
LHC tunnel: 16-20 tesla can by 26-33 TeV c.om.

In the $80 \mathrm{~km}$ tunnel:For TLEP, then for a superHE-LHC

Optimitation could be at $16 \mathrm{~T}$ field level: collision energy 80 TeV c.o.m. Or $100 \mathrm{TeV}$ for $20 \mathrm{~T}$ dipoles Much better new infrastructure.

However many costs go linearly, or more, with length. Magnet stored energy, beam energy also a concern 


\section{HL-LHC Main Technologies}

- Superconductivity technlogies

- Precision and cryogenic mechanics

- Large equipments and tooling

- Ovens for 5-10 m 900 C high accuracy in vacuum

- Power electronics

- Cryogenic plants and cryo-equipment

- New material development for insulator rad-hard

- Advanced «robotics» (or telemanipulation)

- High vacuum

- Infrastructure:

- Civil engineering (Sc links)

- Electrical engineering

- Cooling and Ventilation and basic infrastructure 


\section{What's next?}

- December 2012: Industry information day (with TIARA/EuCARD): THIS workshop

- June 2013: HL-LHC Project approval by CERN Council(based on EU HEP strategy update of 2013)

- July 2013: Catalog of items under purchase

- December 2013: Set up a forum ITLO to try to get the maximum support form Industry:

- to communicate and to find partner for new development and then construction

- Maximize the Industrial return: a goal of the project is also to increment the EU Industry capability

- 2015: Full funding of project, about $750 \mathrm{MCHF}$ including design and prototyping. Secure about 200 MCHF of external collaboration (USA and Japan)

- 2016-2020: construction and test

- 2021: ready for installation 